\title{
Dampak Stres Akademik dan Cyberloafing terhadap kecanduan Smartphone
}

\author{
Nacep Hamrat ${ }^{1}$, Dede Rahmat Hidayat ${ }^{2}$, Mohamad Syarif Sumantri ${ }^{3}$ \\ ${ }^{123}$ Universitas Negeri Jakarta, Indonesia
}

\begin{abstract}
The purpose of this study was to investigate the effect of academic stress and cyberloafing to smartphone addiction. For this purposed, we conducted a survey from 225 participants of post-graduate student at Universitas Negeri Jakarta. This study was used Structural Equation Modelling (SEM) to evaluate the structural model. The result showed that stress academic positively significant affected both smartphone addiction and cyberloafing. The effect of cyberloafing positively significant on smartphone addiction. Stress academic and cyberloafing simultaneously had a positive significant effect to smartphone addiction.
\end{abstract}

Keywords: smartphone addiction, stress academic, cyberloafing

(1) This is an open access article distributed under the Creative Commons Attribution License, which permits unrestricted use,
distribution, and reproduction in any medium, provided the original work is properly cited. (C2019 by author.

\section{PENDAHULUAN}

Smartphone telah menjadi bagian tak terpisahkan dari kehidupan manusia. Keberadaan ponsel pintar dapat membantu mempermudah segala aktivitas sehari-hari, seperti berkomunikasi, sumber hiburan, penyimpan catatan, dan lain-lain. Keterikatan manusia yang berlebihan terhadap smartphone dapat mengakibatkan kecanduan. Kecanduan smartphone dapat berdampak pada kesehatan penggunanya (Chóliz, 2012; Leung, 2008). Kecanduan smartphone adalah salah satu jenis kecanduan pada teknologi. Kecanduan smartphone mengakibatkan seseorang menggunakan smartphone secara kompulsif dan tidak wajar (Lopez-Fernandez, Männikkö, Kääriäinen, Griffiths, \& Kuss, 2018). Individu dikatakan mengalami ketergantungan smartphone, jika penggunaan smartphone yang bermula wajar kemudian berkembang menjadi masalah sosial sehingga aktivitas individu terganggu (Y. S. Kwon \& Paek, 2016).

Salah satu faktor yang memengaruhi kecanduan smartphone adalah faktor situasional yang mencakup segi psikologis (Agusta, 2016). Individu yang mengalami stres cenderung lebih mudah untuk mengalami kecanduan. Tekanan akademik besar dapat membuat mahasiswa melakukan mekanisme coping dengan cara mengalihkan perhatian pada smartphone yang kemudian menjadi kecanduan. Stres akademik berpengaruh positif signifikan terhadap kecanduan smartphone, semakain tinggi stres akademik yang dialami maka kecenderungan kecanduan smartphone akan semakin besar (Karuniawan \& Cahyanti, 2013; Samaha \& Hawi, 2016).

Kecanduan juga dapat disebabkan oleh perilaku cyberloafing. Cyberloafing adalah perilaku seseorang dalam mengakses internet yang tidak berhubungan dengan pekerjaan yang sedang dikerjakannya (Askew, 2013). Perilaku cyberloafing tidak hanya terjadi di tempat kerja. Mahasiswa di dalam kelas pun tidak luput untuk melakukan cyberloafing. Mahasiswa mengakses konten yang tidak berhubungan dengan perkuliahan yang 
sedang berlangsung. Stres akademik dapat memicu terjadinya cyberloafing pada mahasiswa. Beban perkuliahan yang berat membuat mahasiswa mencari penyalur stres dengan melakukan tindakan escaping berupa cyberloafing. Perilaku cyberloafing yang berkelanjutan dapat berujung pada kecanduan smartphone. Penelitian menyatakan cyberloafing berpengaruh positif dan signifikan terhadap kecanduan smartphone (Gökçearslan, Uluyol, \& Şahin, 2018). Telah banyak penelitian yang membahas mengenai kecanduan smartphone, stres akademik, dan cyberloafing, namun belum ada penelitian yang membahas peran stres akademik dan cyberoafing terhadap kecanduan smartphone. Penelitian ini bertujuan untuk melihat pengaruh antara stres akademik dan cyberloafing terhadap kecanduan smartphone dengan menggunakan model persamaan struktural.

Berdasar pada asumsi tersebut, maka dibentuklah model yang akan digunakan untuk menginvestigasi pengaruh stres akademik dan cyberloafing terhadap kecanduan smartphone. Adapun hipotesis yang diajukan pada penelitian sebagai berikut: 1) H1: stres akademik memiliki pengaruh positif dan signifikan terhadap cyberloafing; 2) H2: stres akademik memiliki pengaruh positif dan signifikan terhadap kecanduan smartphone; 3) H3: cyberloafing memiliki pengaruh positif dan signifikan terhadap kecanduan smartphone; 4) H4: stres akademik dan cyberloafing secara bersama-sama memiliki pengaruh positif dan signifikan terhadap kecanduan smartphone.

\section{METODE}

Penelitian dilakukan pada mahasiswa S2 Pendidikan Dasar Universitas Negeri Jakarta yang terdiri dari 230 orang. Sampel diambil menggunakan rumus slovin dengan galat 0.01 sehingga didapat jumlah sampel 225 orang dengan proporsi seimbang dari setiap angkatan. Data dihimpun dari kuesioner online yang disebar pada responden penelitian menggunakan google form. Responden dapat mengakses kuesioner dari tautan yang telah diberikan. Rata-rata waktu yang dibutuhkan untuk mengisi kuesioner adalah 10 menit. Data pribadi responden terjamin karena responden tidak diwajibkan mencantumkan nama ataupun alamat email.

Pengembangan instrumen diturunkan dari dimensi-dimensi pembentuk variabel stres akademik, cyberloafing, dan kecanduan smartphone. Instrumen stres akademik dikembangkan dari lima dimensi stres akademik yaitu worry about grade, self-expectation stress, study despondency, pressure to study, dan workload (Sun, Dunne, Hou, \& Xu, 2011). Instrumen terdiri dari 20 butir dengan menggunakan skala likert. Dari 20 butir yang diujikan, seluruh butir terbukti valid karena memiliki thitung lebih besar dari ttabel $(\alpha=0.05$, df=28) yaitu 1.701. Nilai koefisien cronbach's alpha instrumen stres akademik adalah 0.94. Instrumen stres akademik dinyatakan reliabel karena memiliki koefisien yang sangat tinggi. Instrumen cyberloafing disusun berdasarkan dimensi-dimensi cyberloafing yaitu social activity, informational activity, leisure activity, dan virtual emotional activity ( $\mathrm{Li} \&$ Chung, 2006). Instrumen terdiri dari 16 butir, terdapat 1 butir gugur sehingga tersisa 15 butir instrumen cyberloafing. Nilai koefisien cronbach's alpha menghasilkan nilai 0.86 , artinya instrumen cyberloafing reliabel. Instrumen kecanduan smartphone diadaptasi dari instrumen kecanduan smartphone oleh Kwon et al., (2013). Dari 24 butir yang diujikan, tedapat 4 butir yang gugur. Nilai koefisien cronbach's alpha instrumen kecanduan smartphone bernilai 0,93, artinya instrumen reliabel dan dapat digunakan untuk mengukur kecanduan smartphone dari responden.

Analisis model persamaan struktural dipilih sebagai analisis yang tepat untuk menguji model dan mengembangkan metode yang dapat benar-benar menjelaskan pengaruh dari variabel stres akademik dan cyberloafing terhadap kecanduan smartphone. Data dianalisis menggunakan software Lisrel 8.80. Tahap pertama dalam analisis adalah menyiapkan data dalam bentuk PRELIS. PRELIS data yang akan dianalisis diuji asumsi statistik terlebih dahulu. Uji yang dilakukan antara missing data test, uji asumsi ukuran sampel, uji data pencilan, uji multikoliniearitas, dan nilai residual. Setelah dilakukan uji asumsi, diketahui bahwa tidak ada data yang hilang dan tidak terdapat data pencilan. Pada uji asumsi ukuran sampel ditentukan bahwa rasio ukuran sampel terhadap jumlah parameter sebesar 5:1 (Bentler, 1998). Selanjutnya berdasar uji normalitas univariat, diketahui bahwa nilai skewness dan kurtosis telah memenuhi asumsi yang dipersyaratkan. Uji linieritas data yang dilakukan menunjukkan bahwa data penelitian telah memenuhi uji asumsi multivariat. Berdasarkan hasil uji Mardia untuk normalitas multivariat, koefisien didapatkan multivariat kurtosis sebesar 1.022. Nilai tersebut dapat dinyatakan signifikan (Mardia, 1970). Analisis data model persamaan struktural yang dibentuk tersaji seperti pada Gambar 1. 


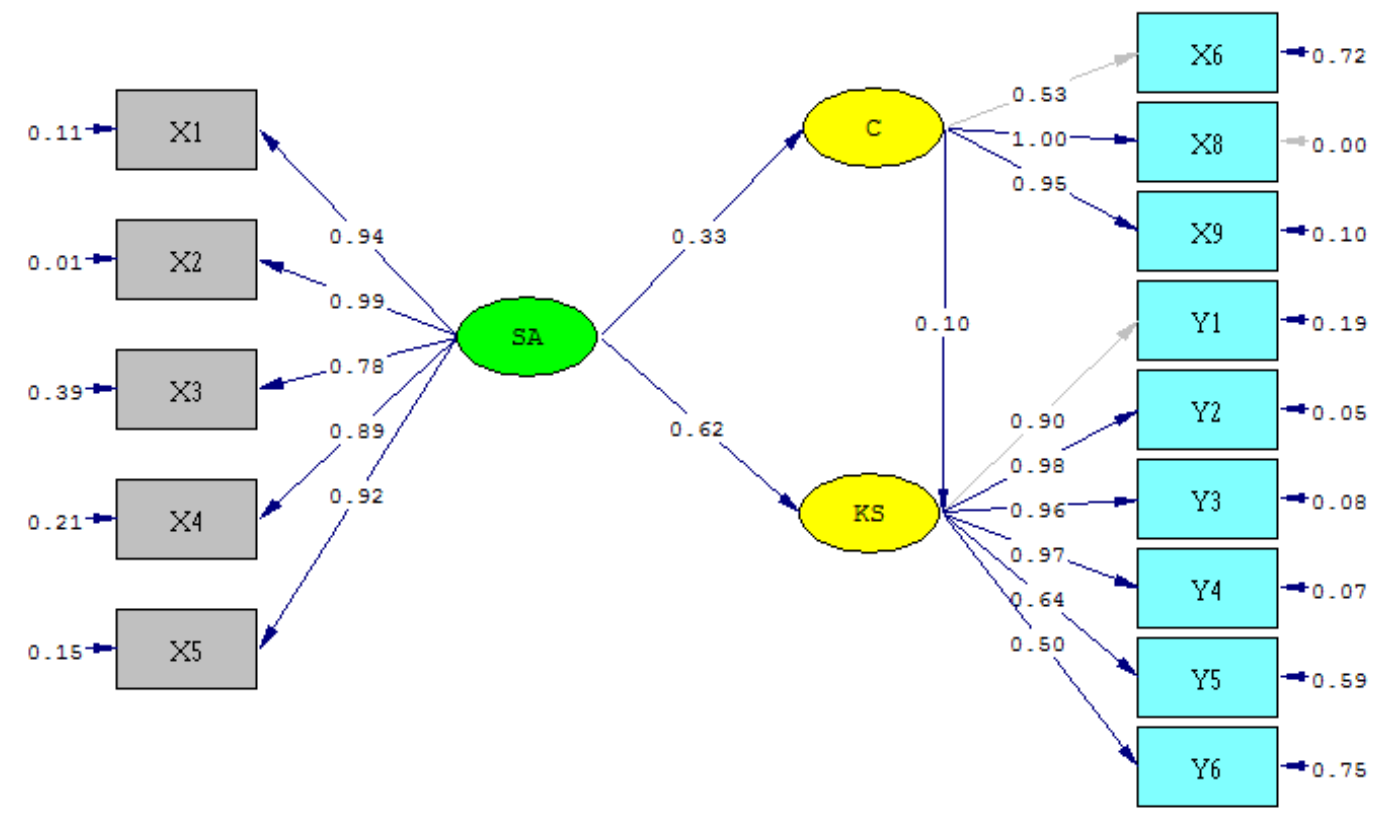

Chi-Square $=2.46, \mathrm{df}=75, \mathrm{P}-\mathrm{value}=1.00000, \mathrm{RMSEA}=0.000$

Gambar 1. Diagram Jalur Model Persamaan Struktural

Asumsi kecocokan model dilakukan untuk mengetahui tingkat kecocokan data dengan model yang dibuat. Model dapat dikategorikan layak jika memenuhi sekurang-kurangnya satu uji kelayakan model (Hair, Black, Babin, \& Anderson, 2009). Uji goodness of fit akan menggunakan uji $\chi 2$, Goodness of Fit Index (GFI), Adjusted Goodness of Fit Index (AGFI), Comparative Fit Index (CFI), Non-Normed Fit Index (NNFI), Normed Fit Index (NFI), Incremental Fit Index (IFI), Root Mean Square Error of Approximation (RMSEA), dan Root Mean Square Residual (RMR).

\section{HASIL}

Temuan penelitian diampilkan ke dalam dua pendekatan yaitu pengukuran model dan persamaan struktur agar dihasilkan penarikan kesimpulan yang bermakna mengenai konstruk teori dan interkorelasi yang terjadi (Anderson \& Gerbing, 1988). Tahap analisis pertama adalah melakukan pengecekan terhadap pengukuran model struktural dan mengevaluasi model struktural yang dibuat untuk menguji hipotesis penelitian. Pengujian model struktural menggunakan tiga jenis uji yaitu absolute fit measures, incremental fit measures, dan parsimony fit measures. Hasil uji pengukuran uji goodness of fit terangkum dalam Tabel 1.

Tabel 1. Rekapitulasi Hasil Uji Goodness of Fit

\begin{tabular}{lccc}
\multicolumn{1}{r}{ Goodness of fit index } & Cut-off value & Hasil & Kesimpulan \\
\hline$\chi^{2}(\mathrm{df}=75, \mathrm{p}=0.05)$ & $<96.22$ & 2.49 & Good fit \\
Sign. Probability & $\geq 0.05$ & 1.00 & Good fit \\
df & $\geq 0$ & 75 & Good fit \\
GFI & $\geq 0.90$ & 1.00 & Good fit \\
AGFI & $\geq 0.90$ & 1.00 & Good fit \\
CFI & $\geq 0.90$ & 1.00 & Good fit \\
TLI/NNFI & $\geq 0.90$ & 1.00 & Good fit \\
NFI & $\geq 0.90$ & 1.00 & Good fit \\
IFI & $\geq 0.90$ & 1.00 & Good fit \\
RMSEA & $\leq 0.08$ & 0.00 & Good fit \\
RMR & $\leq 0.05$ & 0.00 & Good fit \\
\hline
\end{tabular}

Hasil uji kecocokan menunjukkan bahwa $\chi^{2}$ bernilai rendah. Matriks sampel pada data yang diteliti terindikasi tidak jauh berbeda (cocok) dengan matriks pada populasi yang sebenarnya. Hasil uji lainnya yaitu 
GFI, AGFI, CFI, TLI/NNFI, NFI, dan IFI bernilai lebih besar dari 0.90, artinya model yang diajukan dalam penelitian memiliki kecocokan dengan data sampel. Nilai RMSEA dan RMR pun sangat rendah yang menunjukkan bahwa model telah fit.

Pengukuran selanjutnya adalah pengukuran Confirmatory Factor Analysis (CFA). Uji CFA yang akan dilakukan dengan melihat Standardized Loading Factor (SLF). Butir dari indikator konstruk harus memiliki proporsi varian yang tinggi. Validitas konvergen dari butir skala dinilai dengan melihat loading factor setiap butir. Loading factor dinyatakan valid apabila bernilai lebih dari 0.5. (Hair et al., 2009). Butir yang memiliki loading factor rendah selanjutnya tidak diikutsertakan dalam analisis. Setelah mengeliminasi dimensi yang memiliki loading factor di bawah 0.5, lalu dilakukan pengujian Construct Reliability (CR) untuk melihat validitas konvergen setiap dimensi (Hair et al., 2009). Validitas konvergen bernilai baik jika memiliki nilai CR di atas 0.7. Berdasarkan hasil pengujian didapatkan nilai $\mathrm{CR}$ dari variabel stres akademik $(\mathrm{CR}=0.96)$, cyberloafing $(\mathrm{CR}=0.92)$, dan kecanduan smartphone $(\mathrm{CR}=0.93)$. Ukuran selanjutnya adalah menghitung nilai Average Variance Extracted (AVE) dari setiap konstruk. Nilai kritis AVE harus lebih besar dari 0.5 (Fornell \& Larcker, 1981). Ukuran AVE variabel yang diteliti lebih besar dari 0.05. Berdasarkan hasil pengujian didapatkan nilai AVE variabel stres akademik (AVE=0.82), cyberloafing (AVE=0.73), dan kecanduan smartphone (AVE=0.72). Nilai SLF, CR, dan AVE dari seluruh variabel telah memenuhi good rule of thumb, artinya validitas konvergen berkategori baik atau terkategori sebagai adequate convergence.

Uji validitas diskriminan dilakukan untuk menguji perbedaan antar variabel laten (Hair et al., 2009). Nilai korelasi antar variabel dengan nilai akar kuadrat AVE pada ditunjukkan pada Tabel 2.

Tabel 2. Nilai Korelasi antar Variabel dengan Nilai Akar Kuadrat AVE

\begin{tabular}{lccc}
\multicolumn{1}{c}{ Variabel Laten } & Kecanduan Smartphone & Cyberloafing & Stres Akademik \\
\hline Kecanduan Smartphone & 0.85 & & \\
Cyberloafing & 0.30 & 085 & 0.91 \\
Stres Akademik & 0.65 & 0.33 & \\
\hline
\end{tabular}

Berdasar Tabel 2 terlihat nilai akar kuadrat AVE kecanduan smartphone lebih besar dari nilai korelasi cyberloafing $(0.85>0.29)$, nilai akar kuadrat AVE kecanduan smartphone lebih besar dari nilai korelasi stres akademik (0.85>0.65), serta nilai akar kuadrat AVE cyberloafing lebih besar dari nilai korelasi stres akademik (0.98>0.32). Hasil uji validitas diskriminan menyatakan hasil yang baik.

Tahap kedua adalah membuat pemodelan persamaan struktural (Stevens, 2009). Model persamaan struktural digunakan untuk mengevaluasi model struktural yang telah dibuat. Hasil estimasi struktur jalur dituangkan dalam Tabel 3.

Tabel 3. Hasil Model SEM

\begin{tabular}{|c|c|c|c|c|c|c|}
\hline Kosntruk & SLF & T-value & $\mathbf{R}^{2}$ & $\alpha$ & $\mathbf{C R}$ & AVE \\
\hline Stres Akademik & & & & 0.94 & 0.96 & 0.82 \\
\hline X1: Worry about grade & 0.94 & 18.92 & 0.89 & & & \\
\hline $\mathrm{X} 2$ : Self-expectation stress & 0.99 & 20.88 & 0.99 & & & \\
\hline X3: Study despondency & 0.78 & 14.05 & 0.61 & & & \\
\hline $\mathrm{X} 4:$ Pressure to study & 0.89 & 17.01 & 0.79 & & & \\
\hline X5: Workload & 0.92 & 18.23 & 0.85 & & & \\
\hline Cyberloafing & 0.53 & 10.56 & 0.28 & 0.86 & 0.92 & 0.73 \\
\hline X6: Social activity & 1.00 & 9.26 & 1.00 & & & \\
\hline X8: Leisure activity & 0.95 & 9.08 & 0.90 & & & \\
\hline \multicolumn{7}{|l|}{ X9: Virtual emotional activity } \\
\hline Kecanduan Smartphone & & & & 0.93 & 0.93 & 0.72 \\
\hline Y1: Daily-life disturbance & 0.90 & 9.67 & 0.81 & & & \\
\hline Y2: Positive anticipation & 0.98 & 27.77 & 0.95 & & & \\
\hline Y3: Withdrawl & 0.96 & 26.38 & 0.92 & & & \\
\hline Y4: Cyberspace-oriented relationship & 0.97 & 26.77 & 0.93 & & & \\
\hline Y5: Overuse & 0.64 & 11.47 & 0.41 & & & \\
\hline
\end{tabular}




\begin{tabular}{|c|c|c|c|c|c|c|}
\hline Kosntruk & SLF & T-value & $\mathbf{R}^{2}$ & $\alpha$ & $\mathbf{C R}$ & AVE \\
\hline Y6: Tolerance & 0.50 & 8.21 & 0.25 & & & \\
\hline
\end{tabular}

\section{PEMBAHASAN}

Setelah dilakukan uji goodness of fit dan pengujian model persamaan struktural, diketahui bahwa model persamaan struktural menunjukkan hasil yang baik. Pengujian selanjutnya adalah pengujian model struktural. Pengujian model struktural dilakukan untuk menguji hipotesis penelitian yang diajukan. Dari pengujian model struktural didapatkan persamaan struktural sebagai berikut.

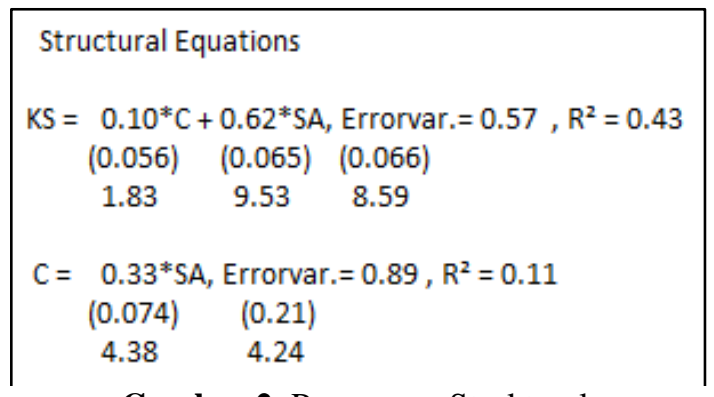

Gambar 2. Persamaan Struktural

Uji signifikansi dilakukan untuk melihat keberartian pengaruh antar variabel laten. Nilai thitung pada persamaan struktural akan dikonsultasikan dengan nilai ttabel. Nilai ttabel dengan derajat bebas $(\mathrm{df})=225-$ $2=223$, dan taraf signifikansi $\alpha=0.05$, adalah 1.645. Pengaruh antar variabel laten dinyatakan signifikan jika thitung lebih besar dari ttabel. Nilai koefisien jalur dari variabel stres akademik terhadap cyberloafing sebesar 0.33. Nilai koefisien jalur tersebut bernilai positif, artinya semakin tinggi stres akademik, maka akan semakin tinggi cyberloafing yang dialami mahasiswa. Uji signifikansi pengaruh stres akademik terhadap cyberloafing bernilai 4.38, nilai tersebut dikonsultasikan pada ttabel. Nilai thitung (4.38) lebih besar dari nilai ttabel (1.645), maka pengaruh antara variabel stres akademik dan cyberloafing adalah signifikan. Dengan demikian, H1 yang diajukan tedukung. Hasil penelitian menyatakan bahwa mahasiswa melakukan mekanisme coping untuk mengatasi stres akademik yang dialaminya. Penelitian lain memiliki hasil serupa bahwa stres berpengaruh positif dan signifikan terhadap cyberloafing (S \& Cahyadin, 2012; Şen, Tozlu, Ateşoğlu, \& Özdemİr, 2016). Tuntutan akademik yang besar saat mahasiswa berada di dalam kelas dapat membuat mahasiswa mengalihkan perhatiannya dari tekanan yang dihadapinya dengan mengakses internet di luar topik perkuliahan. Mahasiswa secara sembunyi-sembunyi mengakses internet menggunakan ponsel pintarnya.

Dalam persamaan struktural, nilai koefisien jalur dari stres akademik terhadap kecanduan smartphone adalah 0.62. Hal tersebut menunjukkan bahwa terdapat pengaruh positif antara stres akademik terhadap kecanduan smartphone. Semakin tinggi stres akademik yang dialami mahasiswa, maka semakin tinggi pula kecenderungan kecandungan smartphone yang dialaminya. Uji t memberikan hasil 9.53. Nilai thitung lebih besar dari ttabel, maka pengaruh antara stres akademik terhadap kecanduan smartphone signifikan. Dengan demikian, H2 yang diajukan terdukung. Hasil penelitian menunjukkan bahwa stres akademik yang tinggi akan meningkatkan kecanduan mahasiswa terhadap kecanduan smartphone. Hal ini sejalan dengan penelitian sebelumnya bahwa stres akademik berpengaruh positif dan signifikan terhadap kecanduan smartphone (Karuniawan \& Cahyanti, 2013). Semakin tinggi risiko kecanduan smartphone, semakin tinggi tingkat stres akademik (Samaha \& Hawi, 2016). Segala faktor yang akan meningkatkan stres akademik akan pula meningkatkan kecenderungan kecanduan pada smartphone.

Koefisien jalur antara cyberloafing terhadap kecanduan smartphone bernilai nilai 0.10. Nilai koefisien jalur antara cyberloafing terhadap kecanduan smartphone bernilai positif. Semakin tinggi perilaku cyberloafing mahasiswa, maka akan semakin cenderung kecanduan smartphone yang dialami. Kemudian pengaruh cyberloafing terhadap kecanduan smartphone diuji signifikansinya menggunakan uji t. Hasil uji t menunjukkan nilai 1.83. Nilai thitung lebih besar dari ttabel, maka pengaruh cyberloafing terhadap kecanduan smartphone signifikan. Dengan demikian, H3 yang diajukan terdukung. Cyberloafing berpengaruh positif dan signifikan terhadap kecanduan smartphone. Yellowlees \& Marks (2007) mengatakan bahwa cyberloafing berpengaruh signifikan terhadap kecanduan smartphone, game online dan internet. 
Koefisien jalur stres akademik (0.62) lebih besar daripada koefisien jalur cyberlofing (0.10). Hal tersebut menunjukkan kontribusi pengaruh stres akademik terhadap kecanduan smartphone lebih besar daripada cyberloafing. Nilai signifikansi pengaruh simultan antara stres akademik dan cyberloafing terhadap kecanduan smartphone adalah 8.59. Nilai tersebut lebih besar dari ttabel sehingga pengaruh stres akademik dan cyberloafing bersama-sama terhadap kecanduan smartphone adalah signifikan. Dengan demikian, H4 yang diajukan terdukung. Stres akademik yang tinggi dan disertai dengan perilaku cyberloafing akan menambah kecenderungan kecanduan smartphone. Koefisien determinasi (R2) pada persamaan struktural adalah 0.43, artinya $43 \%$ variansi total dari variabel kecanduan smartphone dapat dijelaskan oleh persamaan struktural. Besarnya kecanduan smartphone dapat dijelaskan sebesar $43 \%$ oleh variabel stres akademik dan cyberloafing, sedangkan sisanya sebesar $57 \%$ dijelaskan oleh variabel-variabel lain seperti pola asuh, regulasi diri, dan lainlain.

\section{KESIMPULAN}

Berdasarkan hasil penelitian yang dilakukan dapat disimpulkan bahwa secara parsial stres akademik memiliki pengaruh positif dan signifikan baik terhadap cyberloafing maupun kecanduan smartphone. Cyberloafing berpengaruh positif dan signifikan terhadap kecanduan smartphone. Pada pengujian pengaruh secara bersama-sama membuktikan bahwa stres akademik dan cyberloafing secara simultan berpengaruh positif dan signifikan terhadap kecanduan smartphone. Kecanduan smartphone sebanyak $43 \%$ dipengaruhi oleh stres akdemik dan cyberloafing. Pengaruh stres akademik terhadap kecanduan smartphone lebih besar daripada cyberloafing memengaruhi kecanduan smartphone. Keterbatasan dalam penelitian ini adalah data hanya diambil dari satu program studi dalam satu universitas saja. Pada penelitian selanjutnya sampel penelitian dapat diperluas dengan mengambil data dari berbagai program studi dari beberapa universitas. Penelitian selanjutnya pun dapat dikembangkan dengan mengekspolrasi faktor lain yang memoderasi kecanduan smartphone di kalangan mahasiswa

\section{REFERENSI}

Agusta, D. (2016). Faktor-Faktor Resiko Kecanduan Menggunakan Smartphone. E-Journal Bimbingan Dan Konseling, 5(3), 86-96.

Anderson, J. C., \& Gerbing, D. W. (1988). Structural Equation Modeling in Practice: A Review and Recommended Two-Step Approach. Psychological Bulletin, 103(3), 411-423. https://doi.org/10.1037/0033-2909.103.3.411

Askew, K. (2013). The relationship between cyberloafing and task performance and an examination of the theory of planned behavior as a model of cyberloafing. Dissertation Abstracts International: Section B: The Sciences and Engineering, 73(12-B(E)), No Pagination Specified. https://doi.org/10.1088/14686996/16/2/025006

Bentler, P. M. (1998). Comparative Fit Indexes in Structural Models. Psychological Methods, 22(4), 541-562. https://doi.org/10.1037/1082-989X.3.4.424

Chóliz, M. (2012). Mobile-Phone Addiction in Adolescence: The Test of Mobile Phone Dependence (TMD). Progress in Health Sciences, 2(1), 33-44. Retrieved from http://search.ebscohost.com/login.aspx ?direct=true\&profile=ehost\&scope=site\&authtype=crawler\&jrnl=2 0831617\&AN=78040680\&h=wphb8c4wPyj5YcT1/vqPudXDBkNUljaaRiQjdQ6NKMAYG/VOmymP2F qL/WjgIEElaALzzXRkxi26TNJ9EtX4zQ==\&crl=c

Fornell, C., \& Larcker, D. F. (1981). Evaluating Structural Equation Models with Unobservable Variables and Measurement Error. Journal of Marketing Research, 18(1), 39-50. https://doi.org/10.2307/3151312

Gökçearslan, Ş., Uluyol, Ç., \& Şahin, S. (2018). Smartphone addiction, cyberloafing, stress and social support among university students: A path analysis. Children and Youth Services Review, 91(February), 47-54. https://doi.org/10.1016/j.childyouth.2018.05.036

Hair, J. F., Black, W. C., Babin, B. J., \& Anderson, R. E. (2009). Multivariate Data Analysis (7th Edition) (7th ed.). Prentice Hall.

Karuniawan, A., \& Cahyanti, I. Y. (2013). Hubungan antara Academic Stress dengan Smartphone Addiction pada Mahasiswa Pengguna Smartphone. Jurnal Psikologi Klinis Dan Kesehatan Mental, 2(1), 16-21. https://doi.org/10.1002/ejoc.201200111

Kwon, M., Lee, J. Y., Won, W. Y., Park, J. W., Min, J. A., Hahn, C., ... Kim, D. J. (2013). Development and Validation of a Smartphone Addiction Scale (SAS). PLoS ONE, 8(2). https://doi.org/10.1371/journal.pone.0056936 
Kwon, Y. S., \& Paek, K. S. (2016). The influence of smartphone addiction on depression and communication competence among college students. Indian Journal of Science and Technology, 9(41). https://doi.org/10.17485/ijst/2016/v9i41/103844

Leung, L. (2008). Linking Psychological Attributes To Addiction and Improper Use of the Mobile Phone Among Adolescents in Hong Kong. Journal of Children and Media, 2(2), 93-113. https://doi.org/10.1080/17482790802078565

Li, S. M., \& Chung, T. M. (2006). Internet function and Internet addictive behavior. Computers in Human Behavior, 22(6), 1067-1071. https://doi.org/10.1016/j.chb.2004.03.030

Lopez-Fernandez, O., Männikkö, N., Kääriäinen, M., Griffiths, M. D., \& Kuss, D. J. (2018). Mobile gaming and problematic smartphone use: A comparative study between Belgium and Finland. Journal of Behavioral Addictions, 1-12. https://doi.org/10.1556/2006.6.2017.080

Mardia, K. V. (1970). Measures of Multivariate Skewness and Kurtosis with Principal Components. Japanese Journal of Applied Statistics, 57(3), 519-530. https://doi.org/10.5023/jappstat.36.139

S, H. S. R., \& Cahyadin, M. (2012). The Moderation Effect of Commitment To Supervisor and Internet Expertise on Work Stressor and Employee Cyberloafing : The Study on Employee of Local Government of Surakarta. Journal of Indonesian Economy and Business, 27(2), 2012.

Samaha, M., \& Hawi, N. S. (2016). Relationships among smartphone addiction, stress, academic performance, and satisfaction with life. Computers in Human Behavior, 57, 321-325. https://doi.org/10.1016/j.chb.2015.12.045

Şen, E., Tozlu, E., Ateşoğlu, H., \& Özdemİr, A. (2016). the Effects of Work Stress on Cyberloafing Behavior in Higher Education Institutions. 2016(October), 523-535.

Stevens, J. P. (2009). Applied Statistics for The Social Sciences Fifth Edition. In Group. https://doi.org/10.4324/9780203843130

Sun, J., Dunne, M. P., Hou, X. yu, \& Xu, A. qiang. (2011). Educational stress scale for adolescents: Development, validity, and reliability with Chinese students. Journal of Psychoeducational Assessment, 29(6), 534-546. https://doi.org/10.1177/0734282910394976

Yellowlees, P. M., \& Marks, S. (2007). Problematic Internet use or Internet addiction? Computers in Human Behavior, 23(3), 1447-1453. https://doi.org/10.1016/j.chb.2005.05.004 